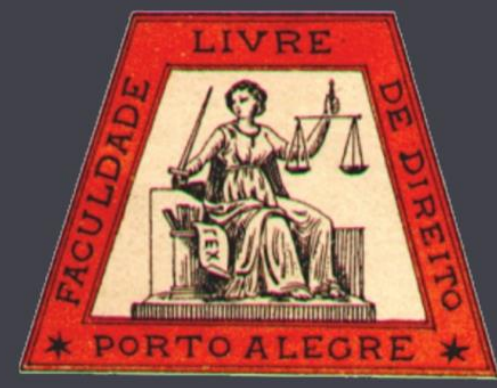

\title{
Neoconstitucionalismo, discricionariedade e decisão judicial: um diálogo entre Robert Alexy e Lênio Luiz Streck
}

Neoconstitutionalism, judicial discretion and decision: a dialogue between Robert Alexy and Lênio Luiz Streck

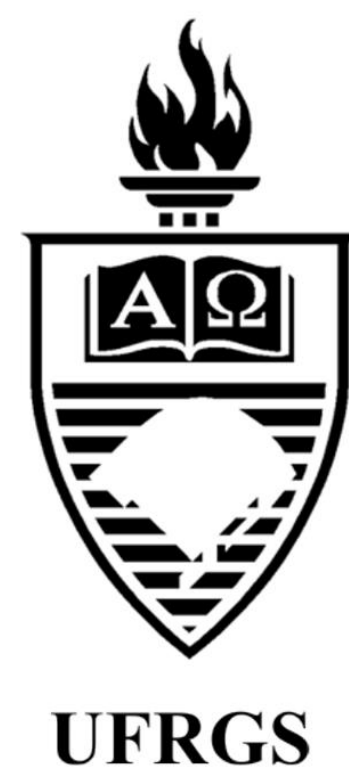

Ana Lucia Pretto Pereira

Centro Universitário Brasil

Bruna de Oliveira Cordeiro

Centro Universitário Brasil 


\title{
Neoconstitucionalismo, discricionariedade e decisão judicial: um diálogo entre Robert Alexy e Lênio Luiz Streck*
}

\author{
Neoconstitutionalism, judicial discretion and decision: a dialogue between Robert Alexy and Lênio
}

Luiz Streck

Ana Lucia Pretto Pereira**

Bruna de Oliveira Cordeiro ${ }^{* * *}$

\begin{abstract}
REFERÊNCIA
PEREIRA, Ana Lucia Pretto; CORDEIRO, Bruna de Oliveira. Neoconstitucionalismo, discricionariedade e decisão judicial: um diálogo entre Robert Alexy e Lênio Luiz Streck. Revista da Faculdade de Direito da UFRGS, Porto Alegre, n. 35, vol. esp., p. 131-148, dez. 2016.
\end{abstract}

\section{RESUMO}

$\mathrm{O}$ presente artigo visa discutir questões relacionadas à interpretação do direito sob o movimento teórico chamado neoconstitucionalismo, a partir de contribuições teóricas de Robert Alexy e Lenio Luiz Streck. A abordagem iniciará, dentre outros aspectos, por considerações sobre o neoconstitucionalismo, seguida pela interpretação do direito com o uso de regras e princípios de acordo com Robert Alexy, concluindo com a proposta de Lênio Luiz Streck, segundo a qual uma decisão judicial será legítima se fundada em uma interpretação sistemática do direito adequada aos princípios informadores de uma determinada comunidade política. Uma vez que a proposta de Robert Alexy acerca da interpretação judicial sobre direitos fundamentais atribui uma considerável margem de discricionariedade ao julgador, ela se aproxima do que Streck chama de escolha judicial, em lugar de decisão judicial, o que seria criticável, segundo Streck.

\section{PALAVRAS-CHAVE}

Neoconstitucionalismo. Decisão judicial. Interpretação constitucional.

\begin{abstract}
This paper aims to discuss questions regarding legal interpretation under the theoretical movement called neoconstitutionalism, from the theoretical contributions of Robert Alexy and Lenio Luiz Streck. The paper will cover some considerations on neoconstitutionalism, followed by the use of principles and rules as means to interpret law, according to Robert Alexy, ending with the proposal presented by Lenio Luiz. Streck, according to which a judicial decision should be legitimate only if based on a systematic interpretation of law, suited to the informative principles of a certain political community. Once the proposal of Robert Alexy on judicial interpretation of fundamental rights allows a considerable margin of discretion to judges, it comes closer to what Streck calls judicial choice, instead of judicial decision, which would be worthy of criticism, according to Streck.
\end{abstract}

\section{KEYWORDS}

Neoconstitutionalism. Judicial decision. Constitutional interpretation.

\section{SUMÁRIO}

Introdução. 1. Neoconstitucionalismo: algumas considerações. 2. Colisão entre regras e princípios: a contribuição de

\footnotetext{
* O presente texto corresponde ao trabalho de conclusão de semestre de Bruna de Oliveira Cordeiro, apresentado à disciplina Filosofia do Direito e Constituição, ministrada pela Profa. Ana Lucia Pretto Pereira, no Programa de Mestrado em Direito do Centro Universitário Autônomo do Brasil - UniBrasil, no primeiro semestre letivo de 2016.

** Mestre e Doutora pela Universidade Federal do Paraná. Professora no Programa de Pós-Graduação em Direito Mestrado do Centro Universitário Autônomo do Brasil - UniBrasil. E-mail: anapereira@unibrasil.com.br. Lattes: http://lattes.cnpq.br/1636566579454782.

*** Mestre pelo Centro Universitário Autônomo do Brasil - UniBrasil. Professora na Escola de Direito do UniBrasil e da Faculdade de Educação Superior do Paraná - FESP. E-mail: bruna_oliveiracordeiro@hotmail.com. Lattes: http://lattes.cnpq.br/2950763830038345
} 
Robert Alexy. 3. Decisão judicial e discricionariedade: a crítica de Lênio Streck. Considerações finais. Referências.

\section{INTRODUÇÃO}

A busca pelo Poder Judiciário com o objetivo de reparar ou evitar lesão a direito fundamenta-se no art. $5^{\circ}$, inciso XXXV da Constituição Federal, que abriga o conhecido princípio da inafastabilidade do controle jurisdicional, de que se pode extrair o direito fundamental de acesso à justiça. ${ }^{1}$

O Estado, ao contemplar dentre suas funções a atividade jurisdicional de resolução de conflitos, tem como dever proporcionar aos jurisdicionados os meios adequados para que se realize o efetivo acesso à justiça. E a realização do acesso à justiça, na esfera judicial, pressupõe análise e interpretação do direito por parte de seu aplicador, no caso, o juiz.

$\mathrm{O}$ princípio constitucional do acesso à justiça não está restrito apenas à possibilidade de o cidadão buscar o Poder Judiciário para ver assegurados os seus direitos; relaciona-se, também, à vinculação estatal no sentido de oferecer uma resposta que resulte em efetiva prestação jurisdicional, mediante uma interpretação que dê efetividade a direitos, considerando as necessidades dos cidadãos à luz da legislação vigente. $\mathrm{O}$ agente que interpreta

\footnotetext{
${ }^{1}$ Sobre o conteúdo do princípio do acesso à justiça, lembra Nelson Nery que não se limita à possibilidade de recorrer ao Poder Judiciário para que se tenham assegurados direitos, indo além para contemplar, também, a resposta estatal efetiva à demanda que lhe seja submetida: "Pelo princípio constitucional do direito de ação, além do direito ao processo justo, todos têm o direito de obter do Poder Judiciário a tutela jurisdicional adequada, sem o que estaria vazio de sentido o princípio. Quando a tutela adequada para o jurisdicionado for medida urgente, o juiz, preenchidos os requisitos legais, tem de concedê-la, independentemente de haver a lei autorizado ou, ainda, que haja lei proibindo a tutela urgente." NERY JR., Nelson. Princípios do processo civil na Constituição Federal. São Paulo: Revista dos Tribunais, 2010. p. 187.
}

materiais jurídicos consciente das limitações e contingências inerentes a essa atividade opera melhor a aplicabilidade do direito.

No presente artigo, verificar-se-á, inicialmente, a interpretação do direito nos moldes do movimento teórico conhecido como neoconstitucionalismo. Em seguida passar-se-á a abordar dois elementos importantes que constituem este trabalho interpretativo, quais sejam: as regras e os princípios, segundo a visão de Robert Alexy. Após estas ponderações, abordar-se-á, no último tópico, como o juiz poderá interpretar a norma jurídica de acordo com os fundamentos do neoconstitucionalismo, na visão de Lenio Streck. Robert Alexy aponta princípios e regras como mecanismos que possibilitam elucidar as principais dificuldades interpretativas levantadas pelo neoconstitucionalismo. Tais mecanismos são especialmente trabalhados, pelo autor, no momento do sopesamento entre valores conflitantes para a solução de um caso concreto. Já Lenio Luiz Streck afasta-se de tais ferramentas ao postular que soluções para casos concretos, no contexto das dificuldades teóricas incorporadas pelo neoconstitucionalismo, deverão ser operadas com base em uma intepretação do direito que leve em consideração a construção desse mesmo direito dentro de uma comunidade política. Vale dizer, que considere, de uma maneira sistemática, como vem sendo interpretada a constituição e a legislação infraconstitucional por seus operadores.

\section{Neoconstitucionalismo: algumas} considerações

O princípio da inafastabilidade do controle jurisdicional vem sendo construído ao longo da história, sendo possível afirmar que sua 
conformação atual resulta da evolução de sistemas jurídicos de tradição anglo saxã (common law) e codificada do direito (civil law). Em países cujo sistema jurídico é informado, preponderantemente, pelo direito costumeiro, uma ideia seminal da proteção judicial de liberdades pode remeter ao art. 39 da Magna Carta de 1215, que preceituava que nenhum homem livre seria privado de sua liberdade, exilado, condenado ou de qualquer forma aniquilado, sem o devido processo legal (due process of law). ${ }^{2}$

No caso da Constituição Brasileira de 1988, o princípio da inafastabilidade do controle jurisdicional é direito fundamental, e está previsto no artigo $5^{\circ}, \mathrm{XXXV}$, da Constituição Federal, segundo o qual "a lei não excluirá da apreciação do judiciário lesão ou ameaça a direito". Com efeito, e, visando extinguir qualquer possibilidade de atos arbitrários executados por autoridades públicas, bem como pretendendo evitar abusos cometidos no período ditatorial, a Constituição brasileira de 1988 estabeleceu o monopólio do Estado para resolver conflitos, como forma de garantir, resguardar e proteger os direitos fundamentais dos indivíduos.

A proteção jurídica de direitos fundamentais, atualmente, exige um esforço analítico sofisticado por parte do intérprete do direito. É possível considerar superada a fase em que a lei era interpretada apenas de forma restritiva, sem qualquer margem para uma análise extensiva e de acordo com o caso concreto apresentado pelo jurisdicionado. Inicialmente, é importante destacar que a Constituição de 1988 foi promulgada com o intuito de ser uma "Constituição Cidadã", com

2 CASTRO MENDES. Aluísio Gonçalves. Breves considerações sobre da questão da inafastabilidade da prestação jurisdicional Texto de conferencia nas IV Jornadas Brasileiras de Direito Processual Civil, Rio de Janeiro, 2007. p. 67. Disponível em http://www.jfrj.gov.br/rev_sjrj/num19/artigos/artigo_3.pdf . Acesso em 14 de março de 2010. direitos fundamentais expressos e com estrutura para serem cumpridos em prol dos cidadãos, afastando-se sobremaneira das Constituições anteriores, em razão das atrocidades e da violação a inúmeros direitos fundamentais no período ditatorial por que passou o Brasil.

Desta forma, os direitos fundamentais tomaram assento especial na Carta Magna, que é, por definição, uma criação política, e não um simples reflexo de uma ordem natural; mais ainda, é a máxima de todas as criações políticas. As constituições refletem a ordem históricoconcreta das sociedades políticas secularizadas e pluralistas. ZAGREBELSKY pontua que não faria sentido propor um novo direito natural com fundamento teológico ou racionalista, posto ser, a Constituição, um acordo político. ${ }^{3} \mathrm{~A}$ Constituição de 1988, seguindo a tendência de positivação, em documentos políticos, de uma carta de direitos, tem a pretensão de estatuir, de forma expressa e insuprimível, todos os direitos necessários para o cidadão viver com dignidade. ${ }^{4}$

Certo positivismo jurídico (sobretudo de Kelsen) tinha como objetivo levar o direito para o mundo da ciência, objetivando-o, sendo um de seus principais traços a "pretensão de criar uma ciência jurídica, com características análogas às ciências exatas e naturais" ${ }^{5}$, visando assegurar segurança jurídica e previsibilidade nas decisões resultantes em normas. Neste sentido, Hans Kelsen sustenta que o direito "é uma ordem normativa da conduta humana, ou seja, um sistema de normas que regulam o comportamento humano". ${ }^{6}$

3 ZAGREBELSKY, Gustavo. El derecho dúctil. Trotta: Madrid, 2007, Capítulo 1, p. 13.

${ }^{4}$ BARROSO, Luís Roberto. Interpretação e aplicação da constituição: fundamentos de uma dogmática transformadora. 4. ed., rev. e atual. São Paulo: Saraiva, 2001.p. 261.

${ }^{5}$ BARROSO, Luís Roberto. Interpretação e aplicação da constituição: fundamentos de uma dogmática transformadora. p. 261.

6 KELSEN, Hans. Teoria Pura do Direito. Trad. João Baptista Machado. São Paulo: Martins Fontes, 2006. p. 04. 
No que diz respeito à ideia de regra, Kelsen afirma que "se quer significar que algo deve ser ou acontecer, especialmente que um homem deve se conduzir de determinada maneira (...) é o sentido do ato através do qual uma conduta é prescrita, permitida ou, especialmente, facultada". ${ }^{7}$

De uma maneira geral, pode-se observar que, no campo do positivismo jurídico, as regras estariam inseridas no contexto de enunciados normativos rígidos, inflexíveis. Entretanto, quanto aos princípios, estes não teriam conteúdo normativo sob o positivismo jurídico, posto que seriam vistos como "enunciados dotados de elevada carga axiológica, baixa densidade normativa e alto grau de indeterminação e abstração", ou seja, não poderiam ser aplicados pela simples subsunção do fato à norma, procedimento este válido, por outro lado, no âmbito do que se convencionou conhecer como regras.

Por ocasião do processo de superação - ao menos em parte - da lógica positivista, percebeuse que a interpretação jurídica pautada apenas sobre regras seria uma interpretação frágil e que deixaria de abranger aspectos importantes do caso concreto. Era necessária a criação de um modelo de interpretação que analisasse a lei com base em seu próprio regramento, e que também permitisse atender às demandas cada vez mais complexas do mundo da vida. E foi diante de um modelo jusnaturalista incompleto e de um positivismo jurídico insuficiente que se abriu possibilidade para discussões em torno da adoção de um novo modelo de interpretação do direito, que fosse capaz de unir a ideologia de

\footnotetext{
${ }^{7}$ BARROSO, Luís Roberto. Interpretação e aplicação da constituição: fundamentos de uma dogmática transformadora. p. 261.

8 SCHIER, Paulo Ricardo. A Constitucionalização do direito no contexto da Constituição de 1988. In: CLÈVE, Clèmerson Merlin; PEREIRA, Ana Lucia Pretto. Direito Constitucional Brasileiro. Tomo 1 (Teoria da Constituição e Direitos Fundamentais). São Paulo: Revista dos Tribunais, 2014. p.98.
}

um Estado de Direito com a sua teoria e seus regramentos normativos. $\mathrm{E}$ foi nesta vertente que teve início o neoconstitucionalismo, em contexto de pós-positivismo. ${ }^{9}$

A Constituição de 1988 foi promulgada já no cenário do neoconstitucionalismo, de modo que sua interpretação passou a representar uma reaproximação entre regras e princípios, estes, agora, com nítido conteúdo deôntico. Este novo modelo interpreta a constituição de uma maneira mais aberta, tendo como principal tarefa desdobrar o universo de possibilidades do direito material. Conforme o entendimento de Susanna POZZOLLO, seria equivocado elencar os direitos fundamentais e os princípios como normas rígidas, posto que sua dimensão material é relevante e, como consequência, precisa ser modulada de acordo com a interpretação da norma em exame. ${ }^{10}$

No campo do neoconstitucionalismo, há preocupação central com a legitimidade da produção do direito no espaço judicial, e também com a plasticidade material e temporal das normas constitucionais, posto que a sociedade não é estática, mas se movimenta e se transforma continuamente. Da mesma forma, o direito constitucional deve ser baseado em uma interpretação modulável, compatível com as necessidades daqueles para quem a Constituição foi criada: para as pessoas. ${ }^{11}$

Para Luís Roberto BARROSO, são características do neoconstitucionalismo: a) a redescoberta dos princípios jurídicos, b) a expansão da jurisdição constitucional com destaque para o surgimento dos tribunais constitucionais; c) desenvolvimento de novos métodos e princípios para a interpretação do

\footnotetext{
9 SANCHÍS, Luis Prieto. Neoconstitucionalismo y ponderacion judicial. In: CARBONELL, Miguel. Neoconstitucionalismo(s). Trotta: Madrid, 2003. p.123. ${ }^{10}$ POZZOLLO, Susanna. Um constitucionalismo ambíguo. In: CARBONELL, Miguel. Neoconstitucionalismo(s). Trotta: Madrid, 2003. p.189.

11 SCHIER, Paulo Ricardo. A Constitucionalização do direito no contexto da Constituição de 1988. p.101.
} 
direito, este visto agora como continente tanto de regras quanto de princípios. ${ }^{12}$

Nesse caminho, em que pese a interpretação mais flexível e abrangente tenha surgido sob o neoconstitucionalismo, os elementos que propiciaram esta modulação foram constituídos ainda anteriormente. A afirmação não quer significar que o período atual e o precedente sejam os mesmos, mas sim, que a construção de um foi essencial para $o$ desenvolvimento do outro. De qualquer maneira, o neoconstitucionalismo incorpora direitos $\mathrm{e}$ garantias prestacionais, direitos que são interpretados por meio de um quadro interpretativo de aproximação entre o direito e a moral, e entre o cidadão e o acesso à justiça. ${ }^{13}$

Nesta vertente neoconstitucionalista, Paulo Ricardo SCHIER, de maneira coincidente a Luis Prieto Sanchís (e este com Alexy, Zagreblesky e Guastini), entende que as principais características deste modelo seriam:

(i) maior presença da constituição em detrimento da lei; (ii) maior presença do juiz em detrimento do legislador; (iii) maior participação dos princípios em detrimento das regras; (iv) mais ponderação e menos subsunção; (v) vinculação do Estado à Constituição como "limitação", mas também como "prestação" e legitimação material; (vi) maior heterogeneidade axiológica dos textos constitucionais e, logo, mais pluralismo; (vii) aproximação entre direito e moral; (viii) ênfase na substância, sem contudo abandono da forma, do procedimento e, finalmente, (ix) eixo teórico fundado na teoria da argumentação sob perspectiva do pós-positivismo. ${ }^{14}$

Nesse caminho, verifica-se claramente que o modelo neoconstitucionalista trouxe ao ordenamento jurídico novos meios de interpretação do texto constitucional e da legislação, de uma forma geral, utilizando-se,

\footnotetext{
${ }^{12}$ BARROSO, Luís Roberto. Interpretação e aplicação da constituição: fundamentos de uma dogmática transformadora. p. 22.

13 SCHIER, Paulo Ricardo. A Constitucionalização do direito no contexto da Constituição de 1988. p.101-102.

${ }^{14}$ SCHIER, Paulo Ricardo. A Constitucionalização do
} direito no contexto da Constituição de 1988. p.101-102. para tanto, de regras e princípios, ambos entendidos como normas jurídicas. Neste aspecto, segundo Robert ALEXY, o direito é um conjunto de normas que podem ser elencadas tanto como regras quanto como princípios e que, havendo conflito entre os valores que contêm (ou, que se lhes atribuem), deverá ocorrer o sopesamento ou ponderação. ${ }^{15}$

Acerca da interpretação do direito no constitucionalismo e no neoconstitucionalismo, importante considerar que:

\begin{abstract}
(...) a interpretação do direito no contexto teórico do neoconstitucionalismo deve ser compreendida diferente mente do modelo interpretativo do Direito no paradigma do positivismo jurídico (em sua versão exegético-legalista). $\mathrm{Na}$ medida em que o neoconstitucionalismo considera insuficiente $\mathrm{o}$ modelo Juspositivista composto exclusivamente por regras para a solução de casos controversos, essa nova corrente introduz os princípios como elemento chave para solucioná-los, e, assim, fornecer uma nova dogmática dos direitos fundamentais. ${ }^{16}$
\end{abstract}

E é justamente neste aspecto que algumas considerações merecem ser destacadas. A primeira delas é no que concerne à possibilidade de duas ou mais respostas para um mesmo caso concreto. Ou então, quando uma mesma resposta pode incorporar comandos normativos diversos, como no caso de "a mesma dignidade humana que foi invocada como fundamento para vedar pesquisas com células-tronco também foi invocada como fundamento para autorizálas." ${ }^{17}$. Em caso de um aparente conflito entre dois direitos, como deverá agir o seu operador, a fim de viabilizar ao jurisdicionado a efetividade

15 ALEXY, Robert. Teoria dos direitos fundamentais. Trad. Virgílio Afonso da Silva. São Paulo: Malheiros, 2011.p.99.

${ }^{16}$ MATOS, Daniel Ortiz; BARBA, Rafael Giorgio Dalla. Do juspositivismo ao neoconstitucionalismo: Porque ainda apostamos na discricionariedade. In: BERNARDI, Renato; NEVES, Fabiana. Função Política do Processo II. Jacarezinho: UENP \& Instituto Ratio Juris, 2014. (Anais do IV Simpósio Internacional de Análise Crítica do Direito).

17 SCHIER, Paulo Ricardo. A Constitucionalização do direito no contexto da Constituição de 1988. p.16. 
de seu direito? De que maneira esses direitos poderão ser ponderados, e até que limite? É o que o próximo tópico pretende abordar.

\section{Colisão entre regras e princípios: a} contribuição de Robert Alexy

Para Robert Alexy, necessário que o ordenamento jurídico seja interpretado não somente no campo do formalismo, entendido este como a utilização de um modelo puro de regras, mas também sob um aspecto substantivo, ou seja, próximo ao de um modelo puro de princípios, uma adequação entre estes dois conceitos, com fundo no pluralismo jurídico e também político. ${ }^{18}$

Se utilizássemos apenas o formalismo, estaríamos deixando de lado todo o aspecto dos princípios, valores e fatos sociais de determinada comunidade, e como consequência, estaríamos trabalhando apenas com a racionalidade. Por outro lado, se utilizássemos apenas o substancialismo, o jurisdicionado estaria à mercê de questões até mesmo arbitrárias, de julgamentos baseados apenas em subjetividades. ${ }^{19}$

E inicialmente, antes de tratarmos acerca da resolução de conflitos entre regras e/ou entre princípios, importante trazer algumas considerações sobre a diferenciação entre regras e princípios para, somente após esta análise, passarmos a desvendar as formas de resolução do conflito entre estas duas espécies de normas jurídicas.

Em sua obra "Teoria dos direitos fundamentais", Robert Alexy, com base na distinção de Dworkin, entende que as normas podem ser divididas em duas espécies: princípios e regras. Enquanto princípios são considerados, segundo Robert Alexy, como "mandamentos de otimização", as regras "são normas que são sempre ou satisfeitas ou não satisfeitas. Regras contêm, portanto, determinações no âmbito daquilo que é fática e juridicamente possível. Isso significa que a distinção entre regras e princípios é uma distinção qualitativa, e não uma distinção de grau." Nesta vertente, Robert Alexy entende que "toda norma é ou uma regra ou um princípio." 20

\begin{abstract}
Enquanto as regras são normas, imediatamente descritivas, na medida em que estabelecem obrigações, permissões e proibições mediante a descrição da conduta a ser adotada, os princípios são normas imediatamente finalisticas, já que estabelecem um estado de coisas para cuja realização é necessária a adoção de determinados comportamentos. Daí possuírem caráter deônticoteleológico: deôntico, porque estipulam razões para a existência de obrigações, permissões ou proibições;teleológico, porque as obrigações, permissões e proibição decorrem dos efeitos advindos de determinado comportamento que preservam ou promovem determinado estado de coisas. Já as regras podem ser definidas como normas mediatamente finalisticas, ou seja, normas que estabelecem indiretamente fins, para cuja concretização estabelecem com maior exatidão qual o comportamento devido. Daí possuírem caráter deôntico-deontológico: deôntico, porque estipulam razões para a existência de obrigações, permissões ou proibições; deontológico, porque as obrigações, permissões ou proibições decorrem de uma norma que indica "o que" deve ser feito. ${ }^{21}$
\end{abstract}

Contudo, talvez a distinção mais importante feita por Robert Alexy seja a de que os princípios são vistos como "mandamentos de otimização", ou seja, uma norma que estabelece que algo seja realizado na maior medida possível, dentro das possibilidades fáticas e jurídicas existentes. Desta forma, os princípios podem ser cumpridos em diferentes graus, mas dependem, de uma forma ou de outra, tanto da possibilidade real como jurídica. Já as regras são normas determinadas, que podem ser cumpridas

\footnotetext{
${ }^{18}$ ZAGREBELSKY, Gustavo. El derecho dúctil. p.115.

${ }^{19}$ ZAGREBELSKY, Gustavo. El derecho dúctil. p.115-
} 116.

${ }^{20}$ ALEXY, Robert. Teoria dos direitos fundamentais. p.90.
${ }^{21}$ ALEXY, Robert. Teoria dos direitos fundamentais. p.72. 
ou não, ou seja, deve-se fazer exatamente o que elas exigem, em sua integralidade. ${ }^{22}$

Nesta vertente, segundo Robert Alexy:

As regras são normas imediatamente descritivas, primariamente retrospectivas e com pretensão de decidibilidade e abrangência, para cuja aplicação se exige a avaliação da correspondência. Sempre centrada na finalidade que lhes dá suporte ou nos princípios que lhes são axiologicamente sobrejacentes, entre a construção conceitual da descrição normativa e a construção conceitual dos fatos.Os princípios são normas imediatamente finalísticas, primariamente prospectivas e com pretensão de complementaridade e de parcialidade, para cuja aplicação se demanda uma avaliação da correlação entre estado de coisas a ser promovido e os efeitos decorrentes da conduta havida como necessária à sua promoção. ${ }^{23}$

Ultrapassada a distinção entre regras e princípios, importante agora analisar qual a solução, segundo Robert Alexy, para um conflito entre regras, entre princípios e também entre regras e princípios, e qual o papel do juiz para a busca da melhor decisão.

Inicialmente, quanto à colisão entre regras, Robert Alexy propõe que seja inserida uma exceção na norma, a fim de que se encontre a melhor solução para o caso concreto:

Um exemplo para um conflito entre regras que pode ser resolvido por meio da introdução de uma cláusula de exceção é aquele entre a proibição de sair da sala de aula antes que o sinal toque e o dever de deixar a sala se o alarme de incêndio tiver soado, essas regras conduzem a juízos concretos de deverser contraditórios entre si. Esse conflito deve ser solucionado por meio da inclusão, na primeira regra, de uma cláusula de exceção para o caso do alarme de incêndio. ${ }^{24}$

Contudo, quando não for possível a utilização de uma cláusula de exceção, dever-seá declarar uma das normas em conflito como inválidas para a aplicação naquele caso em exame, ou seja, "pelo menos uma das regras tem

\footnotetext{
${ }^{22}$ ALEXY, Robert. Teoria dos direitos fundamentais. p.90.

${ }^{23}$ ALEXY, Robert. Teoria dos direitos fundamentais. p.7879.

${ }^{24}$ ALEXY, Robert. Teoria dos direitos fundamentais. p.91-
} 92. que ser declarada inválida e, com isso, extirpada do ordenamento jurídico." 25

Já quando houver uma colisão entre princípios, a sistemática de resolução do conflito, segundo Robert Alexy, se mostra totalmente diversa. Nesse caso, uma norma terá que ceder em detrimento da outra, para a solução do caso concreto. Entretanto, nenhuma das normas precisará ser considerada como inválida, mas, tão somente, inaplicável naquele caso e para aquelas circunstâncias.

De acordo com Robert Alexy "conflitos entre regras ocorrem na dimensão da validade, enquanto as colisões entre princípios - visto que só princípios válidos podem colidir - ocorrem para além dessa dimensão, na dimensão do peso." 26 Entretanto, quando os princípios possuem a mesma categoria abstrata - e não se é possível desprezar nenhum deles - dever-se-á utilizar o sopesamento, ou seja, a análise de princípios que possuem a mesma valoração e que, no caso concreto, necessitarão ser priorizados. Assim, para melhor elucidação acerca desta interpretação, Robert Alexy explica que:

Os princípios colidentes no caso da incapacidade para participar de audiência processual serão chamados de $P^{1}$ (direito à vida e à integridade física) e $P^{2}$ (operacionalidade do direito penal). Isoladamente considerados, $P^{1}$ e $P^{2}$ levariam a juízos concretos de dever-ser contraditórios entre si: $P^{1}$ levaria a "é proibido realizar a audiência", e $P^{2}$ a "é obrigatória a realização da audiência". Essa colisão pode ser resolvida ou por meio do estabelecimento de uma relação de precedência incondicionada ou por meio do estabelecimento de uma relação de precedência condicionada. ${ }^{27}$

Diante destes aspectos, pode-se compreender a ponderação nos seguintes termos: "As condições segundo as quais um princípio precede a outro constituem o suposto de fato de

\footnotetext{
${ }^{25}$ ALEXY, Robert. Teoria dos direitos fundamentais. p.9192.

${ }^{26}$ ALEXY, Robert. Teoria dos direitos fundamentais. p.93.

${ }^{27}$ ALEXY, Robert. Teoria dos direitos fundamentais. p.96.
} 
uma regra que expressa a consequência jurídica do princípio precedente." ${ }^{28}$ Esta análise nos leva ao conceito de mandamentos de otimização, antes citado. Nos mandamentos de otimização, a interpretação é a de que não existem relações absolutas de precedência e nem tampouco normas apenas quantificáveis, mas sim, existe uma proximidade entre a teoria dos princípios e dos valores, a qual leva para o caminho do sopesamento e ponderação realizadas no âmbito das decisões judiciais. ${ }^{29}$

Nesses termos e, de acordo com a análise levada a efeito por Robert Alexy, a ponderação nas decisões judiciais poderia ser utilizada em caso de conflitos entre princípios, já que com estes é compatível a estrutura de mandamento de otimização.

Já se deu a entender que há uma conexão entre a teoria dos princípios e a máxima da proporcionalidade. Essa conexão não poderia ser mais estreita: natureza dos princípios implica a máxima da proporcionalidade, e essa implica aquela. Princípios são mandamentos de otimização em face das possibilidades jurídicas e fáticas. A máxima da proporcionalidade em sentido estrito, ou seja, exigência de sopesamento,decorre da relativização em face das possibilidades jurídicas. A máxima da proporcionalidade em sentido estrito decorre do fato de princípios serem mandamentos de otimização em face das possibilidades jurídicas. Já as máximas da necessidade e da adequação decorrem da natureza dos princípios como mandamentos de otimização em face das possibilidades fáticas. ${ }^{30}$

Desta forma, falar em ponderação ou sopesamento nas decisões judiciais é tratar da resolução de conflitos entre princípios compatíveis para um mesmo caso concreto. Aqui, conforme entendimento de Robert Alexy, a ponderação seria aplicável aos princípios, já

\footnotetext{
${ }^{28}$ AMORIM, Leticia Balsamão. A distinção entre regras e princípios segundo Robert Alexy - Esboço e Critica Revista de Informação Legislativa. Brasília, a. 42, n. 165, jan./mar. 2005.p.126.

${ }^{29}$ AMORIM, Leticia Balsamão. A distinção entre regras e princípios segundo Robert Alexy. p.126.

30 ALEXY, Robert. Teoria dos direitos fundamentais.
} p.116-118. que as regras são normas determinadas, que devem ser cumpridas ou não.

Com efeito, verificou-se até aqui que a análise de uma decisão com base em regras e princípios tomou corpo a partir do neoconstitucionalismo, o qual trouxe a possibilidade ao magistrado de em caso de conflitos entre regras e /ou princípios utilizar-se de métodos de interpretação como a ponderação e o sopesamento.

A ponderação, tal qual proposta por Robert Alexy, constitui método de solução de conflitos entre bens e valores fundamentais de igual relevância em um ordenamento jurídico. A proporcionalidade, mecanismo essencial ao método da ponderação, segundo Robert Alexy, é a ferramenta que permitirá conhecer a racionalidade das decisões que resultem na prevalência de um ou outro bem juridicamente relevante. Compreender direitos fundamentais como mais bem adaptáveis à estrutura de mandamentos de otimização, de acordo com Alexy, permite solucionar casos concretos construindo o que o autor chama de norma de direito fundamental atribuída. ${ }^{31} \mathrm{~A}$ norma de direito fundamental atribuída é uma construção teórica que reconhece, ao julgador, legitimidade para a criação de soluções jurídicas em casos concretos.

\section{Decisão judicial e discricionariedade: a crítica de Lenio Streck}

Quando se fala sobre o neoconstitucionalismo, uma das primeiras ideias que surge para discussão é a utilização da ponderação na análise de decisões judiciais, a qual outorgaria aos magistrados a possibilidade de decidirem da forma que entendessem mais coerente, dando azo a uma possível

\footnotetext{
${ }^{31}$ PEREIRA, Ana L.P. O conteúdo e alcance do art. 5. ${ }^{\circ}, \S$ 1. ${ }^{\circ}$, da CF/1998. In: CLÈVE, PEREIRA, Direito Constitucional Brasileiro, p.138.
} 
discricionariedade. "Essa questão assume foros de dramaticidade se levarmos em conta o panprincipiologismo que domina a doutrina e a jurisprudência. Trata-se de uma espécie de 'bolha especulativo-principiológica', pela qual o jurista/intérprete, na falta de uma lei adequada ou até mesmo da norma constitucional, lança mão de um catálogo interminável de princípios." "32

Se anteriormente à Constituição de 1988 uma autêntica experiência de Estado Democrático encontrava-se sensivelmente prejudicada, e, por este aspecto, o espaço para decisões totalmente discricionárias e sem qualquer embasamento constitucional adequado era consideravelmente mais amplo, atualmente, de posse de uma constituição democrática, que prega a dignidade da pessoa humana, a isonomia, a transparência e a aplicabilidade imediata de direitos fundamentais, parece que, por vezes, ainda nos encontramos "presos" a certa discricionariedade desregrada e sem qualquer embasamento constitucional. ${ }^{33} \mathrm{~A}$ aderência ao neoconstitucionalismo e, como consequência, à aplicabilidade dos princípios em decisões judiciais e, em caso de conflito, de regras interpretativas de sopesamento e mandamentos de otimização ${ }^{34}$, não quer significar abertura de espaço para decisões desarrazoadas, tomadas exclusivamente sobre subjetividades, mas, sim, que o julgador tenha a possibilidade de, em caso de conflitos ou até mesmo de lacuna na lei, realizar uma interpretação constitucional para solucionar o caso em análise. ${ }^{35}$

Neste sentido, Lenio Streck expõe sua consideração acerca de como uma decisão

\footnotetext{
${ }^{32}$ STRECK, Lenio Luiz. Hermenêutica jurídica e(m) crise: uma exploração hermenêutica da construção do direito. 8 ed. rev. atual. Porto Alegre: Livraria do Advogado, 2009.p.97.

${ }^{33}$ STRECK, Lenio Luiz. Hermenêutica jurídica e(m) crise. p.101.

${ }^{34}$ ALEXY, Robert. Teoria dos direitos fundamentais. p.93.

${ }^{35}$ STRECK, Lenio Luiz. O que é isto - decido conforme minha consciência? 4 ed. rev. Porto Alegre: Livraria do Advogado Editora, 2013.p.106.
}

judicial deve ser interpretada nos moldes do neoconstitucionalismo:

Essa resposta (decisão) não pode - sob pena de ferimento do "princípio democrático" - depender da consciência do juiz, do livre convencimento, da busca da "verdade real", para falar apenas nesses artifícios que escondem a subjetividade "assustadora" do julgador (ou do interprete em geral, uma vez que a problemática aqui discutida vale, a toda evidencia, igualmente para a doutrina). ${ }^{36}$

Lenio Streck faz uma diferenciação entre decisão e escolha. Segundo o autor, " $a$ decisão jurídica - não pode ser entendida como um ato em que o juiz, diante de várias possibilidades possíveis para a solução do caso concreto, escolhe aquela que lhe pareça mais adequada. Com efeito, decidir não é sinônimo de escolher." ${ }^{37}$ A escolha, aos olhos de Streck, “(...) é um ato de opção que se desenvolve sempre que estamos diante de duas ou mais possibilidades, sem que isso comprometa algo maior do que o simples ato presentificado em uma dada circunstância."

Trazendo essa diferenciação para a análise da interpretação do direito, pode-se compreender que, julgar um caso com base no que o magistrado entenda como mais adequado, seria o mesmo que se utilizar do panprincipiologismo ${ }^{38}$ para basear suas decisões, ou seja, de "um álibi para decisões que ultrapassam os próprios limites semânticos do texto constitucional" ${ }^{39}$ De acordo

${ }^{36}$ STRECK, Lenio Luiz. O que é isto - decido conforme minha consciência? p.106.

${ }^{37}$ STRECK, Lenio Luiz. O que é isto - decido conforme minha consciência? p.107.

38 De acordo com Suelen da Silva Webber, o panprincipiologismo poderia ser entendido como a forma que os magistrados se utilizam para proferir decisões discricionárias e até mesmo arbitrárias, com base em pseudoprincípios, o que impossibilita que o Estado concretize os direitos sociais da população. WEBBER, Suelen da Silva. O panprincipiologismo como propulsor da arbitrariedade judicial. In. Revista Eletrônica de Direitos Fundamentais e Democracia. Curitiba, v. 13, no. 13, p. 305-324, jan-junho de 2013.

${ }^{39}$ STRECK, Lenio Luiz. Hermenêutica jurídica $\mathrm{e}(\mathrm{m})$ crise. p. 214-215. 
com Lenio Streck, "a decisão se dá, não a partir de uma escolha, mas, sim, a partir do comprometimento com algo que se antecipa. No caso da decisão jurídica, esse algo que se antecipa é a compreensão daquilo que " $a$ comunidade política constrói como direito." 40 Nesta vertente, Lenio Streck argumenta que "combater a discricionariedade, o ativismo, o positivismo fático, etc (...) quer dizer compromisso com a Constituição e com a legislação democraticamente construída" ${ }^{41}$

E julgar de acordo com o "compromisso com a Constituição" nada mais é do que o julgador se utilizar de regras e princípios constitucionais que são, em consenso geral, princípios que devem ser respeitados tanto pelos legisladores, quanto por aplicadores do direito. Entretanto, não se pode confundir estas considerações com uma interpretação desregrada, operada à revelia de todo o instrumental jurídico disponível, construído e trabalhado pela comunidade política, o que seria criticável, de acordo com Lenio Streck.

Entender o direito como construção de uma comunidade política é tese encontrável, com certas distinções, também no pensamento de Ronald Dworkin. Dworkin propunha que direito legítimo é direito construído "em cadeia", à maneira de um romance escrito por várias mãos. Por ser romance construído em cadeia, com começo, meio e solução de continuidade compartilhados por todos os seus "escritores", é que surge um outro conceito trabalhado por Dworkin, qual seja: integridade. Integridade enquanto coerência decorrente da observância de princípios (morais) informadores de uma comunidade política que assim se reconhece, e que age como tal. ${ }^{42}$

\footnotetext{
${ }^{40}$ STRECK, Lenio Luiz. O que é isto - decido conforme minha consciência? p.108.

${ }^{41}$ STRECK, Lenio Luiz. O que é isto - decido conforme minha consciência? p.112.

${ }^{42}$ Por essa razão, a resposta que se atribua a pergunta formulada por Menelick de Carvalho Netto, e também por
}

Como consequência dessa atividade interpretativa, surgem críticas quanto ao seguinte aspecto: qual seria a linha tênue entre a liberdade de interpretar e a discricionariedade sem qualquer embasamento no direito construído por uma comunidade política (como coloca Streck) ou, até mesmo, fundada em uma espécie de panprincipiologismo?

Conforme exposto no tópico I do presente texto, a Constituição Federal de 1988, conhecida como "Constituição Cidadã", foi promulgada visando superar as atrocidades cometidas contra os cidadãos no período por que passou o Brasil. E por ter este escopo, a Constituição foi elaborada de forma analítica, ou seja, uma Carta Constitucional que pretende abarcar o maior número de direitos possíveis, e de forma expressa em seu texto. ${ }^{43}$

Entretanto, verificou-se que ao longo da história e da aplicabilidade do texto constitucional, a fim de se outorgar um efetivo acesso do jurisdicionado aos seus direitos, surgiu a necessidade de abertura da Constituição, a fim de que também fossem garantidos direitos importantes, o que cedeu terreno para decisões judiciais informadas por uma moral subjetiva. "Consequência disso é que a positivação daqueles valores e princípios se deu por meio de expressões vagas, elásticas e imprecisas, dando aos seus intérpretes - no caso, legisladores e julgadores, em sentido estrito - a tarefa de

Vera Karam de Chueiri, é determinante para que se compreenda o sentido de constituição válido para uma determinada comunidade política. À pergunta "O que uma constituição constitui?", Vera Karam de Chueiri responde: "Uma constituição constitui uma comunidade política que se reconheça como tal". Para que uma comunidade política se reconheça como tal, é fundamental que seus membros participem, com efetividade, do processo (público) de tomada de decisões que conformam a sua constituição. Sobre o tema: PEREIRA, Ana Lucia Pretto. Atividade política da jurisdição constitucional brasileira. (no prelo) 43 PEREIRA, Ana L.P. Jurisdição constitucional na Constituição Federal de 88: entre ativismo jurídico e autocontenção. In: Revista Eletrônica Direitos Fundamentais e Democracia. $2007 . \quad$ Disponível http://revistaeletronicardfd.unibrasil.com.br. p.09. 
interpretar a aplicar aqueles valores através de uma tomada de posição moral, no intuito de lhes dar concreção." 44

Atualmente, verifica-se um grande esforço do Poder Judiciário no sentido de solucionar questões que, muitas vezes, dispensariam serem submetidas à apreciação judicial, podendo ter sido resolvidas dentre os Poderes Legislativo ou Executivo, por exemplo. Entretanto, as possibilidades, agora mais ampliadas, de interpretação atribuem ao magistrado maior liberdade para a análise do material jurídico disponível. Nesse caminho, um mesmo caso concreto poderá ter como solução diferentes respostas, pois não mais prevalece a tese segundo a qual as soluções jurídicas para casos concretos encontram-se previamente desenhadas dentro de uma moldura normativa. A resposta correta, tal qual proposta por Dworkin, e a qual depende de um esforço judicial dirigido a aproximar-se da figura ideal do juiz Hércules, só pode ser, na visão do autor, a seguinte: $a$ melhor possivel. ${ }^{45}$

A aplicação do princípio da unidade constitucional é um bom exemplo da utilização da hermenêutica jurídica e de uma interpretação "íntegra” do direito, conforme propõe Dworkin. Esse princípio carrega conteúdo deôntico no sentido que deve existir coerência na leitura das normas constitucionais, sobretudo quanto a interpretação for realizada com base na ponderação, para a solução de colisões. Também se pode citar o princípio da integridade, anteriormente citado, para se buscar uma resposta correta e de acordo com a Constituição. Como exemplo da utilização desse princípio na interpretação do caso concreto, Ronald Dworkin traz a figura do juiz Hércules, citada anteriormente, representativa de magistrado que

44 PEREIRA, Ana L.P. Revista Eletrônica Direitos Fundamentais e Democracia. 2007. p.09.

45 DWORKIN, Ronald. O Império do Direito. Trad. Jefferson Luiz Camargo. São Paulo: Martins Fontes, 1999.p.230. baseia suas decisões em princípios morais. Como caso ilustrativo, Dworkin explica que o juiz Hércules terá que julgar o caso McLoughlin, no qual se pleiteia uma indenização por dano moral. Para tanto, o juiz Hércules considera distintas hipóteses, as quais podem ou não conceder a indenização por danos morais pleiteada. Tudo depende de uma leitura da situação concreta à luz do direito em construção pela comunidade política. "O direito como integridade pede que os juízes admitam, na medida do possível, que o direito é estruturado por um conjunto coerente de princípios sobre a justiça, a equidade e o devido processo legal adjetivo, e pede-lhes que os apliquem nos novos casos que se lhes apresentem, de tal modo que a situação de cada pessoa seja justa e equitativa segundo as mesmas normas. $" 46$

No caso fíctício exposto, o juiz Hércules admite ter considerado a sua própria convicção sobre o que fosse mais justo e equitativo para as partes envolvidas. Lenio Streck, ao analisar o caso em questão, entende que o juiz Hércules, ao decidir com base em “(...) princípios jurídicos com objetivos políticos, coloca à disposição dos juristas/intérpretes um manancial de possibilidades para a construçãolelaboração de respostas coerentes com o direito positivo - o que confere uma blindagem contra discricionariedade (se assim se quiser, pode-se chamar isso de "segurança jurídica") - e com grande preocupação contemporânea do direito: a pretensão de legitimidade." Do ponto de vista de Lenio Streck, como antes observado, uma decisão adequada ao neoconstitucionalismo não resultará, propriamente, de uma escolha, mas sim de uma continuidade coerente em relação à interpretação do material jurídico disponível e legítimo, qual seja, a Constituição e a correspondente legislação infraconstitucional.

O neoconstitucionalismo não apresenta quais seriam os critérios metodológicos

${ }^{46}$ DWORKIN, Ronald. O Império do Direito. p.291 
adequados para a interpretação da norma, mas também não os despreza. Por esse motivo, é necessário que haja um estágio de elevado desenvolvimento da interpretação no campo do neoconstitucionalismo, alcançado com o "correto aproveitamento dos critérios argumentativo-procedimentais, como a razoabilidade, a proporcionalidade, a coerência e a universalidade, não só no mérito e no direito processual, mas também no debate sobre a metodologia constitucional(...)". ${ }^{47}$ A verdade é que não existe uma "formula pronta" acerca de quais métodos interpretativos deveriam ser utilizados para se afastar o risco de decisões arbitrárias, de modo que muitas propostas teóricas ocupam-se da racionalidade das decisões judiciais.

Os métodos de sopesamento, ponderação, exclusão de uma regra, declaração de invalidade de uma norma, não possuem nenhuma efetividade se não forem utilizados de acordo com o núcleo essencial do neoconstitucionalismo, que é a interpretação do direito à luz da constituição. Humberto Ávila tece considerações quanto à forma que entende correta para a interpretação constitucional:

[...] pode-se afirmar que o intérprete não só constrói, mas reconstrói sentido, tendo em vista a existência de significados incorporados ao uso lingüístico e construídos na comunidade do discurso. [...] Daí se dizer que interpretar é construir a partir de algo,por isso significa reconstruir: a uma porque utiliza como ponto de partida os textos normativos, que oferecem limites à construção de sentidos; a duas, porque manipula a linguagem, à qual são incorporados núcleos de sentidos, que são, por assim dizer, constituídos pelo uso, e preexistem ao processo interpretativo individual. ${ }^{48}$

\footnotetext{
${ }^{47}$ MOREIRA, Eduardo Ribeiro. Neoconstitucionalismo e Interpretação. In: Revista da EMERJ, v. 11, n. 43, 2008. p.17.

48 ÁVILA, Humberto. Teoria dos Princípios. 3. ed.. São Paulo: Malheiros, 2003.

p.33-34.
}

\section{J.J Gomes Canotilho observa que o}

objetivo da interpretação é o resultado prático da resolução do conflito:

\begin{abstract}
Interpretar as normas constitucionais significa (como toda a interpretação de normas jurídicas) compreender, investigar e mediatizar o conteúdo semântico dos enunciados linguísticos que formam o texto constitucional. A interpretação jurídicoconstitucional reconduz-se, pois, à atribuição de um significado a um ou vários símbolos lingüísticos escritos na constituição. Esta interpretação faz-se mediante a utilização de determinados critérios (ou medidas) que se pretendem objectivos, transparentes e científicos (teoria ou doutrina da hermenêutica). ${ }^{49}$
\end{abstract}

Nesta vertente, em que pese não se encontre no neoconstitucionalismo uma única forma correta de interpretar a lei (mas tão somente que esta seja analisada de acordo com os regramentos constitucionais), é certo que as diversas teorias que o integram concorrem no sentido de que "o Direito é constructo axiológico e teleológico, que impõe a compreensão da necessidade de conciliar legalidade $e$ legitimidade no desenvolvimento da interpretação constitucional". ${ }^{50}$

Finalmente, observa-se que a liberdade atribuída aos julgadores para interpretar uma norma e/ou um caso concreto não poderá ultrapassar a linha tênue entre a possibilidade de interpretação da norma e o risco de decisões arbitrárias. $\mathrm{O}$ escopo de interpretação da lei, de acordo o neoconstitucionalismo, deve ser entendido como "uma fundamentação da fundamentação", ou seja, "compromisso com a constituição e com a legislação democraticamente construída", pois somente desta forma teremos a verdadeira aplicabilidade

49 CANOTILHO, J. J. Gomes. Direito constitucional e teoria da constituição. Coimbra: Almedina, 1998.

${ }^{50}$ SOARES, Ricardo Maurício Freire. A interpretação constitucional: uma abordagem filosófica. In: NOVELINO, Marcelo. Leituras complementares de direito constitucional: controle de constitucionalidade e hermenêutica constitucional. 2.ed. Salvador: JusPodivm, 2008. p. 112 . 
da constituição ao caso concreto, o respeito aos princípios fundamentais, dentre eles o do acesso à justiça e, como consequência, o combate a eventuais arbitrariedades. ${ }^{51}$

\section{Considerações finais}

É certo que o neoconstitucionalismo é o espaço teórico onde se encontram mecanismos que conferem maior liberdade interpretativa ao julgador. Por meio das propostas trazidas pelo neoconstitucionalismo foi possível visualizar a necessidade de que o jurídico se adequasse a um novo modelo de interpretação da lei, distanciando-se das limitações impostas por certo positivismo e adotando um método mais maleável, baseado na construção de direito legítimo permeado/trespassado pela moral e pela política.

Em nosso ordenamento jurídico, o juiz não é mais considerado apenas a "boca da lei", mas sim, possui uma responsabilidade importante de interpretar a lei com base na constituição, primeiramente, sem descuidar de todos os aspectos sociais existentes em nosso contexto de comunidade. De fato, se antes o princípio do acesso à justiça era apenas conceituado como a possibilidade de o cidadão pleitear seu direito perante o Poder Judiciário, agora este conceito possui contornos muito mais extensos, pois se trata também de alcançar uma decisão coerente, de acordo com a Carta Magna, e ao mesmo tempo fundamentada em normas rígidas $\mathrm{e}$ consubstanciadas em nossa legislação.

As categorias teóricas trazidas por Robert Alexy, sobretudo aquelas construídas sobre o terreno da interpretação - não raro difícil - de direitos fundamentais, contribuem para uma melhor elucidação quanto ao valor atribuído, pelos ordenamentos jurídicos contemporâneos, a

\footnotetext{
${ }^{51}$ STRECK, Lenio Luiz. O que é isto - decido conforme minha consciência?.p.111.
}

esses direitos, implicando em uma interpretação jurídica capaz de solucionar casos concretos com certa dose de racionalidade. A crítica de Lenio Streck, no sentido de que soluções judiciais para casos concretos devem resultar de decisões alinhadas ao direito - sempre em construção - de uma determinada comunidade política, e não de escolhas, muitas vezes arbitrárias e dissonantes quanto à experiência jurídico-normativa dessa mesma comunidade, revela-se importante para reduzir, sensivelmente, a margem de discricionariedade atribuída pelo sistema para a resolução de casos difíceis. É certo que, sob o neoconstitucionalismo, o direito dialoga com a política e a moral (objetiva e subjetiva). Todavia, evitar a absorção completa do direito tanto pela política, quanto pela moral, pressupõe uma vigilância constante por parte de seus operadores, mormente no que toca a sistemas jurídicos que carreguem, normativamente, certa pretensão de integridade. 


\section{REFERÊNCIAS}

ALEXY, Robert. Teoria dos direitos fundamentais. Trad. Virgílio Afonso da Silva. São Paulo: Malheiros, 2011.

AMORIM, Leticia Balsamão. A distinção entre regras e princípios segundo Robert Alexy - Esboço e Critica - Revista de Informação Legislativa. Brasília, a. 42, n. 165, jan./mar. 2005.

ÁVILA, Humberto. Teoria dos Princípios. 3. ed.. São Paulo: Malheiros, 2003.

BARROSO, Luís Roberto. Interpretação e aplicação da constituição: fundamentos de uma dogmática transformadora. 4. ed., rev. e atual. São Paulo: Saraiva, 2001.

. A nova interpretação constitucional: ponderação, direitos fundamentais e relações privadas. Rio de Janeiro: Renovar, 2003.

Prefácio - "O Estado Contemporâneo, os Direitos Fundamentais e a Redefinição da Supremacia do Interesse Público”, p. XII-XIII. In: Interesse Público vs. Interesse Privado. Rio de Janeiro: Lumen Juris, 2007.

CANOTILHO, J. J. Gomes. Direito constitucional e teoria da constituição. Coimbra: Almedina, 1998.

CASTRO MENDES, Aluísio Gonçalves. Breves considerações sobre da questão da inafastabilidade da prestação jurisdicional. Texto de conferência na IV Jornadas Brasileiras de Direito Processsual Civil, Rio de Janeiro, $2007 . \quad$ Disponível em: <http://www.jfrj.gov.br/rev_sjrj/num19/artigos/artigo_3.pdf>.

DWORKIN, Ronald. O Império do Direito. Trad. Jefferson Luiz Camargo. São Paulo: Martins Fontes, 1999.

KELSEN, Hans. Teoria Pura do Direito. Trad. João Baptista Machado. São Paulo: Martins Fontes, 
2006.

MATOS, Daniel Ortiz; BARBA, Rafael Giorgio Dalla. Do juspositivismo ao neoconstitucionalismo: Porque ainda apostamos na discricionariedade. In: BERNARDI, Renato; NEVES, Fabiana. Função Política do Processo II. Jacarezinho: UENP \& Instituto Ratio Juris, 2014. (Anais do IV Simpósio Internacional de Análise Crítica do Direito).

MOREIRA, Eduardo Ribeiro. Neoconstitucionalismo e Interpretação. In: Revista da EMERJ, v. 11, n. 43, 2008 .

NERY JR., Nelson. Princípios do processo civil na Constituição Federal. São Paulo: Revista dos Tribunais, 2010.

PEREIRA, Ana L. P. Jurisdição constitucional na Constituição Federal de 88: entre ativismo e autocontenção. In: Revista Eletrônica Direitos Fundamentais e Democracia. 2007. Disponível em: $<\mathrm{http}: / /$ revistaeletronicardfd.unibrasil.com.br>.

. O conteúdo e alcance do art. 5. ${ }^{\circ}, \S 1 .^{\circ}$, da CF/1998. In: CLÈVE, C. M.; PEREIRA, Ana Lucia P.. Direito Constitucional Brasileiro. T. 1 (Teoria da Constituição e Direitos Fundamentais). São Paulo: Revista dos Tribunais, 2014.

POZZOLLO, Susanna. Um constitucionalismo ambíguo. In: CARBONELL, Miguel. Neoconstitucionalismo(s). Trotta: Madrid, 2003.

SANCHÍS, Luis Prieto. Neoconstitucionalismo y ponderacion judicial. In: CARBONELL, Miguel. Neoconstitucionalismo(s). Trotta: Madrid, 2003.

SCHIER, Paulo Ricardo. A Constitucionalização do direito no contexto da Constituição de 1988. In: CLÉVE, Clémerson Merlin; PEREIRA, Ana Lucia P.. Direito Constitucional Brasileiro. Tomo 1 (Teoria da Constituição e Direitos Fundamentais). São Paulo: Revista dos Tribunais, 2014.

SOARES, Ricardo Maurício Freire. A interpretação constitucional: uma abordagem filosófica. In: NOVELINO, Marcelo. Leituras complementares de direito constitucional: controle de constitucionalidade e hermenêutica constitucional. 2.ed. Salvador: JusPodivm, 2008.

STRECK, Lênio Luiz. Hermenêutica jurídica $e(m)$ crise: uma exploração hermenêutica da construção do direito. 8 ed. rev. atual. Porto Alegre: Livraria do Advogado, 2009.

do Advogado Editora, 2013.

O que é isto - decido conforme minha consciência? 4 ed. rev. Porto Alegre: Livraria

VASCONCELLOS, Fernando Andreoni. Hermenêutica jurídica e derrotabilidade. Curitiba: Juruá, 2010.

WEBBER, Suelen da Silva. O panprincipiologismo como propulsor da arbitrariedade judicial. In: Revista Eletrônica de Direitos Fundamentais e Democracia. Curitiba, v. 13, n. 13, p. 305-324, jan./jun. 2013.

ZAGREBELSKY, Gustavo. El derecho dúctil. Trotta: Madrid, 2007. 
Recebido em: 07/09/2016 Aceito em: 18/10/2016 
